\title{
Decreased Levels of Autoantibody against Histone Deacetylase 3 in Patients with Systemic Sclerosis
}

Yutaka Kuwatsuka ${ }^{1}$, Fumihide Ogawa ${ }^{1}$, Yohei Iwata ${ }^{1}$, Kazuhiro Komura ${ }^{1}$, Eiji Muroi ${ }^{1}$, Toshihide Hara ${ }^{1}$, Motoi Takenaka ${ }^{1}$, Kazuhiro Shimizu ${ }^{1}$, Minoru Hasegawa ${ }^{2}$, Manabu Fujimoto $^{2}$, and Shinichi Sato ${ }^{1}$

${ }^{1}$ Department of Dermatology, Nagasaki University Graduate School of Biomedical Sciences, Nagasaki, Japan and ${ }^{2}$ Department of Dermatology, Kanazawa University Graduate School of Medical Science, Kanazawa, Japan.

Address correspondence to: Dr. Shinichi Sato, Department of Dermatology, Nagasaki University Graduate School of Biomedical Sciences, 1-7-1 Sakamoto, Nagasaki, 852-8501, Japan.

Phone: 81-95-819-7331

Fax: 81-95-849-7335

E-mail: s-sato@nagasaki-u.ac.jp

Short title: Anti-HDAC-3 autoantibody in SSc 


\section{ABSTRACT}

\section{Background}

Systemic sclerosis (SSc) is characterized by immunological abnormalities, especially the production of autoantibodies against various cellular components. Treatment with histone deacetylase (HDAC) inhibitors prevents collagen accumulation in a mouse SSc model. Additionally, autoantibody against HDAC-3 is produced in colon cancer patients, while HDAC-1 and HDAC-2 do not elicit autoantibody response.

\section{Objective}

To determine the presence and levels of antibodies (Abs) against HDAC-3 in SSc.

\section{$\underline{\text { Methods }}$}

Anti-HDAC-3 Ab was examined by enzyme-linked immunosorbent assay (ELISA) and immunoblotting using human recombinant HDAC-3. The HDAC-3 activity was evaluated by ELISA using the fluorimetric histone deacetylase lysyl substrate that comprises an acetylated lysine side chain.

\section{$\underline{\text { Results }}$}

Contrary to our hypothesis that autoimmune background in SSc induced the production of autoantibody against HDACs, IgG and IgM anti-HDAC-3 Ab levels in SSc patients were significantly lower than in normal controls ( $\mathrm{p}<0.0005$ and $\mathrm{p}<0.001$, respectively). Furthermore, decreased levels of IgG anti-HDAC-3 Ab were specific to SSc, since IgG anti-HDAC-3 Ab levels in patients with dermatomyositis (DM) and those with systemic lupus erythematosus (SLE) were similar and slightly increased relative to normal controls, respectively. Immunoblotting analysis showed that anti-HDAC-3 Ab was detected in normal controls and patients with DM or SLE, while it was absent in SSc patients. The HDAC-3 activity was significantly inhibited by IgG isolated from sera of 
normal controls, whereas such inhibitory effect was not observed by IgG isolated from sera of SSc patients.

\section{Conclusion}

These results indicate the lack of anti-HDAC-3 autoantibody in SSc patients, which is produced in healthy individuals as well as DM and SLE patients, suggesting that this autoantibody might function as protective Ab.

\section{$\underline{\text { Keywords }}$}

systemic sclerosis; HDAC-3; autoantibody. 


\section{INTRODUCTION}

Systemic sclerosis (SSc) is a connective tissue disease that is characterized by fibrosis and vascular changes in the skin and other internal organs with autoimmune background ${ }^{[1]}$. A variety of immunologic abnormalities of $\mathrm{T}$ and $\mathrm{B}$ lymphocytes have been detected in SSc ${ }^{[2]}$. Especially, autoantibody production is a central feature of SSc, since they are detected in more than $90 \%$ of SSc patients ${ }^{[3]}$. These autoantibodies in SSc patients react to various intracellular components, such as DNA topoisomerase I, centromere, RNA polymerases, U1RNP, U3RNP, Th/To, and histone ${ }^{[3]}$.

Acetylation and deacetylation of histones play an important role in transcription regulation of eukaryotic cells ${ }^{[4]}$. Acetylation of histone promotes a more relaxed chromatin structure, allowing transcriptional activation. Histone deacetylases (HDACs) can act as transcription repressors, due to histone deacetylation, and consequently promote chromatin condensation ${ }^{[4,5]}$. Thus, HDACs play a key role in the regulation of gene transcription. HDACs are found in all eukaryotic organisms and are divided into four classes: I (HDAC-1, -2, -3, and -8), II (HDAC-4, -5, -6, -7, -9, and -10), III (Sirt-1, $-2,-3,-4,-5,-6$, and -7 ), and IV (HDAC-11) ${ }^{[6-8]}$. HDAC-3 is a $49 \mathrm{kDa}$ protein expressed by many different cell lines and normal human tissues, and is located in the cell nucleus and cytoplasm ${ }^{[9]}$. Several studies have shown that expression of HDACs is upregulated in cancer cells from different tissue organs ${ }^{[10,11]}$. Especially, HDAC-3 and HDAC-1 have more pronounced effect on carcinogenesis ${ }^{[12]}$. HDAC inhibitors have the antineoplastic activities by activating and/or repressing subsets of genes and inducing cell-cycle arrest, cell differentiation, and/or apoptotic cell death in various transformed cells ${ }^{[13-15]}$; for example, trichostatin A (TSA) and suberoylanilide hydroxamic acid (SAHA), both of which are HDAC inhibitors, have pharmacological activity against tumor cells ${ }^{[16]}$. 
Recently, several reports have revealed that HDAC inhibitors have not only antitumor effects, but also anti-inflammatory effects in autoimmune diseases [16-18] . HDAC inhibitors have anti-inflammatory effects by inhibiting activation of key transcription factors and pro-inflammatory cytokines, such as nuclear factor- $\kappa \mathrm{B}$, tumor necrosis factor- $\alpha$, interleukin-1, and interleukin- ${ }^{[19,20]}$. In both mouse and rat collagen-induced rheumatoid arthritis (RA) models, HDAC inhibitors SAHA and MS-275 decrease bone erosion and resorption ${ }^{[19]}$. Furthermore, SAHA or TSA treatment blocks disease progression in the MRL-lpr/lpr mice, a murine model of systemic lupus erythematosus $(\mathrm{SLE})^{[21,22]}$.

Treatment with TSA prevents the accumulation of extracellular matrix in a mouse model of bleomycin-induced skin fibrosis, suggesting that regulation of HDAC function is related to the development of skin fibrosis ${ }^{[23]}$. Recently, autoantibody against HDAC-3 is produced in colon cancer patients, while closely related HDAC-1 and HDAC-2 do not elicit humoral immune response ${ }^{[24]}$. However, the existence and role of autoantibody to HDAC-3 in autoimmune diseases remained unknown. Therefore, we hypothesized that autoimmune background in SSc induced the production of autoantibody against HDAC-3. In this study, the presence or levels of anti-HDAC-3 antibody (Ab) in patients with SSc were investigated and its levels were compared to those with SLE or dermatomyositis (DM) and healthy individuals. 


\section{PATIENTS AND METHODS}

\section{Serum Samples}

Blood samples were obtained from 60 Japanese SSc patients (51 females and 9 males; age, $50 \pm 17$ years). All patients fulfilled the criteria proposed by the American College of Rheumatology ${ }^{[25]}$. These patients were grouped according to the classification system proposed by LeRoy et al. ${ }^{\text {[26]: }} 23$ patients (21 females and 2 males; age $52 \pm 15$ years) had limited cutaneous SSc (ISSc) and 37 patients (30 females and 7 males; age $49 \pm 19$ years) had diffuse cutaneous SSc (dSSc). The disease duration of ISSc and dSSc patients was $10.0 \pm 10.0$ and $3.1 \pm 3.0$ years, respectively. The duration of the disease was calculated from the onset time of the first clinical event (other than Raynaud's phenomenon) that was a clear manifestation of SSc. In addition, 30 patients with SLE, who fulfilled the criteria of American College of Rheumatology ${ }^{[27]}$, and 30 patients with DM, who fulfilled Bohan and Peter's criteria ${ }^{[28,29]}$, were included in this study. None of the SSc, SLE, or DM patients was treated with corticosteroid, D-penicillamine, or other immunosuppressive therapy at their first visit. Patients with malignancy were excluded in this study. Thirty-four age- and sex-matched healthy Japanese individuals (30 females and 4 males; age $47 \pm 16$ years) were used as normal controls. Fresh venous blood samples were centrifuged shortly after clot formation. All samples were stored at $-70^{\circ} \mathrm{C}$ prior to use.

\section{Enzyme-Linked Immunosorbent Assay (ELISA) for Anti-HDAC-3 Ab}

ELISA was performed as previously described ${ }^{[30]}$. Briefly, 96-well plates were coated with human recombinant HDAC-3 $(0.5 \mu \mathrm{g} / \mathrm{ml}$; Carbiochem, Darmstadt, Germany) at 
$4^{\circ} \mathrm{C}$ overnight. The wells were blocked with $2 \%$ bovine serum albumin and $1 \%$ gelatin in Tris-bufferd saline (TBS). After washing twice with TBS, the serum samples diluted to 1:100 in TBS containing 1\% bovine serum albumin were added to triplicate wells and incubated for 90 minutes at $20^{\circ} \mathrm{C}$. After washing 4 times with TBS containing $0.05 \%$ Tween-20, the plates were incubated with alkaline phosphatase-conjugated goat anti-human immunoglobulin (Ig) G or IgM Abs (Cappel, Dyrham, NC, USA) for 1 hour at $20^{\circ} \mathrm{C}$. After washing 4 times with TBS containing $0.05 \%$ Tween-20, substrate solution containing $0.91 \mu \mathrm{g} / \mu \mathrm{l}$ p-nitrophenyl phosphate (Sigma-Aldrich, St. Louis, MO, USA) in diethanolamine buffer (1M diethanolamine and $\left.0.5 \mathrm{M} \mathrm{MgCl}_{2}\right)$ was added and the optical density (OD) of the wells at $405 \mathrm{~nm}$ was subsequently determined.

\section{Immunoblotting}

Human recombinant HDAC-3 (0.5 $\mu \mathrm{g} / \mathrm{lane})$ was subjected to electrophoresis and electrotransferred to nitrocellulose sheets. The nitrocellulose sheets were cut into strips and incubated overnight with serum samples diluted 1:100. Then, the strips were incubated for 1.5 hours with alkaline phosphatase-conjugated goat anti-human IgG Abs (Cappel). Color was developed using 5-bromo-4-chloro-3-indrolyl phosphate and nitro blue tetrazolium (Sigma-Aldrich). Five SSc patients, 5 SLE patients, 5 DM patients, and 5 healthy individuals were evaluated. Serum samples from patients with SLE or DM and healthy individuals whose levels of IgG anti-HDAC-3 Ab were higher than the highest OD value (0.476) of SSc patients by ELISA were selected for immunoblotting analysis. 


\section{HDAC-3 Activity Assay}

IgG was purified from serum samples using magnetic beads coated with recombinant protein G covalently coupled to the surface (Dynal, Lake Success, NY, USA). Final IgG concentration was measured by spectrophotometer (Gene Quant II. Amersham Biosciences, Piscataway, NJ, USA). The HDAC-3 activity was determined by the HDAC fluorimetric assay kit (Biomol International, Inc., LP, USA) according to the manufacturer's protocol. The assay procedure has two steps. First, the fluorimetric histone deacetylase lysyl substrate (Fluor de Lys ${ }^{\mathrm{TM}}$ ) that comprises an acetylated lysine side chain, is incubated with a sample containing HDAC activity. Second, deacetylation of the substrate sensitizes the substrate so that, in the second step, treatment with the Fluor de Lys ${ }^{\mathrm{TM}}$ Developer produces a fluorophore that is excited at wavelength of 360 $\mathrm{nm}$ and detected at $460 \mathrm{~nm}$.

First, $0.2 \mu \mathrm{g}$ of HDAC-3 was incubated with $10 \mu \mathrm{g}$ of purified IgG for 30 minutes at $20^{\circ} \mathrm{C}$. Then, HDAC-3 treated with IgG was incubated with the fluorimetric histone deacetylase lysyl substrate for 10 minutes in triplicate wells of a 96-well ELISA plate, followed by the addition of the Fluor de Lys ${ }^{\mathrm{TM}}$ Developer. Then, OD values were determined at $460 \mathrm{~nm}$. OD values for $0.2 \mu \mathrm{g}$ and $0 \mu \mathrm{g}$ of HDAC-3 untreated with IgG were determined as controls. The mean value for $0.2 \mu \mathrm{g}$ of HDAC-3 untreated with IgG was 5657 arbitrary fluorescence units and the mean value for $0 \mu$ g of HDAC-3 untreated with IgG was 4153 arbitrary fluorescence units. To demonstrate the difference of the HDAC-3 activity for each group, OD values were converted into \%HDAC-3 activity by calculating the ratio of its OD values to controls. Ten SSc patients and 10 healthy individuals were assessed in the current study. Serum samples from healthy 
individuals whose levels of IgG anti-HDAC-3 Ab were higher than the highest OD value (0.476) of SSc patients by ELISA were selected for the HDAC-3 activity assay.

\section{Statistical Analysis}

Statistical analysis was performed using the Mann-Whitney U test for determining the level of significance of differences between sample means and Bonferroni's test for multiple comparisons. A p-value less than 0.05 was considered statistically significant. 


\section{$\underline{\text { RESULTS }}$}

\section{Anti-HDAC-3 Autoantibody by ELISA}

The levels and presence of anti-HDAC-3 Ab in serum samples from patients with collagen diseases and normal controls were assessed by ELISA (Fig. 1). Unexpectedly, IgG anti-HDAC-3 Ab levels significantly decreased in serum samples from SSc patients relative to normal controls $(\mathrm{p}<0.0005)$, those with SLE $(\mathrm{p}<0.0001)$, or those with DM $(\mathrm{p}<0.0001$; Fig. 1A). There was no significant difference in IgG anti-HDAC-3 Ab levels between DM patients and normal controls, while SLE patients exhibited slightly elevated levels of IgG anti-HDAC-3 Ab relative to normal controls $(p<0.05)$. IgG anti-HDAC-3 Ab levels in dSSc patients were similar to those found in ISSc patients $(0.220 \pm 0.082$ vs. $0.230 \pm 0.093)$. Similarly, IgM anti-HDAC-3 Ab levels in SSc patients significantly decreased compared with those in normal controls $(\mathrm{p}<0.001$; Fig. 1B). Unlike IgG anti-HDAC-3 Ab, IgM anti-HDAC-3 Ab levels in DM and SLE patients were significantly lower than those found in normal controls $(p<0.005$, respectively). However, there was no significant difference in IgM anti-HDAC-3 Ab levels between patients with SSc, those with SLE, and those with DM. IgM anti-HDAC-3 Ab levels in dSSc patients did not significantly differ from those in ISSc patients $(0.356 \pm 0.227$ vs. $0.441 \pm 0.300)$. Thus, IgM anti-HDAC-3 Ab levels decreased in SSc, SLE, and DM, while IgG anti-HDAC-3 Ab levels decreased in only SSc.

To determine whether the reduction of anti-HDAC-3 Ab levels in connective tissue disorders was related to total serum Ig levels, we correlated serum Ig levels with anti-HDAC-3 Ab levels. Total serum IgG levels in SSc (1705 \pm 588 mg/dl), SLE (1934 $\pm 630)$, and DM (1752 \pm 438$)$ patients were significantly elevated relative to normal 
controls $(1263 \pm 215, \mathrm{p}<0.01$, respectively). By contrast, total serum IgM levels were similar between SSc patients (195 $\pm 124 \mathrm{mg} / \mathrm{dl})$, SLE patients (120 \pm 59), DM patients (150 \pm 40$)$, and normal controls $(135 \pm 30)$. Furthermore, serum total IgG and IgM levels did not significantly correlate with IgG and IgM anti-HDAC-3 Ab levels in SSc ( $r=-0.13, p=0.31$ and $r=0.28, p=0.13$, respectively). Thus, the reduction of anti-HDAC-3 Ab levels did not reflect total serum Ig levels.

\section{Immunoblotting Analysis for Anti-HDAC-3 Ab}

The presence of IgG anti-HDAC-3 Ab was further evaluated by immunoblotting analysis using human recombinant HDAC-3 (Fig. 2). Serum samples from healthy individuals (lanes 1 and 2), a DM patient (lane 3), and a SLE patient (lane 4), all of whom had higher IgG anti-HDAC-3 Ab levels than the highest OD value of SSc patients by ELISA, exhibited reactivity with HDAC-3 (47 kDa). By contrast, no reactivity with HDAC-3 was observed using sera from SSc patients (lanes 5 and 6). Thus, the presence of IgG anti-HDAC-3 Ab in patients with SLE or DM and normal individuals and the absence of IgG anti-HDAC-3 Ab in patients with SSc were confirmed by immunoblotting analysis.

\section{Inhibition of HDAC-3 Enzymatic Activity by IgG Isolated from Serum Samples}

To determine the functional relevance of anti-HDAC-3 Ab, we assessed whether anti-HDAC-3 Ab was able to inhibit the HDAC-3 enzymatic activity. The HDAC-3 activity was determined by ELISA using the fluorimetric histone deacetylase lysyl substrate that comprises an acetylated lysine side chain. The HDAC-3 activity was inhibited by IgG isolated from serum samples of healthy individuals, all of whom had 
higher IgG anti-HDAC-3 Ab levels than the highest OD value of SSc patients by ELISA, compared with IgG-untreated HDAC-3 (Fig. 3). In contrast, IgG isolated from serum samples of SSc patients did not significantly affect HDAC-3 activity. Furthermore, the HDAC-3 enzymatic activity was more strongly inhibited by IgG isolated from healthy individuals than those from SSc patients $(\mathrm{p}<0.05)$. Thus, IgG isolated from serum samples of normal individuals but not SSc patients was able to inhibit the HDAC-3 enzymatic activity. 


\section{DISCUSSION}

Contrary to our hypothesis that autoimmune background in SSc induced the production of autoantibody against HDAC-3, IgG and IgM anti-HDAC-3 Ab levels significantly decreased in sera from SSc patients relative to normal individuals. Immunoblotting analysis confirmed that anti-HDAC-3 Ab was present in sera from normal individuals whose levels of IgG anti-HDAC-3 Ab were higher than the whole SSc group by ELISA, while it was not detected in sera from SSc patients. Furthermore, IgG isolated from serum samples of normal individuals but not SSc patients was able to inhibit the HDAC-3 enzymatic activity. Thus, the present study is first to reveal the lack of anti-HDAC-3 autoantibody in SSc, which is produced in normal persons.

In this study, IgM anti-HDAC-3 Ab decreased in SSc, SLE, and DM, while IgG anti-HDAC-3 Ab decreased in only SSc, indicating that the defect to produce IgG anti-HDAC-3 Ab was specific to SSc. Since a few studies reported the possibility of class switching of autoantibodies ${ }^{[31]}$, it remained unknown whether or not class switching from IgM to IgG occurred in autoantibodies. However, while some healthy individuals produce IgM Abs with specificities similar to SLE patients, Ig class switching to downstream isotypes is considered to be required for the generation of more functional and pathogenic autoantibodies ${ }^{[32]}$. IgG anti-HDAC-3 Ab detected in normal persons as well as SLE and DM patients might be more functional relevant than IgM Abs. It remained unknown whether the reduction of IgG anti-HDAC-3 Ab was due to reduction of class switching in SSc patients; however, this phenomenon did not just reflect total serum Ig levels, since anti-HDAC-3 Ab levels did not correlate with total serum Ig levels. Although the mechanisms of class switching from IgM to IgG in autoantibodies were unclear, recent studies have shown that exogenous signals, such as 
through CD40 ligation and bacteria-derived lipopolysaccharide, induce production of class-switched autoantibodies in mice ${ }^{[32][33]}$. Such exogenous signals might be related to the difference in IgG anti-HDAC-3 Ab production in SSc, SLE, DM, and normal persons.

Many studies have shown that downregulation of the HDAC activity by HDAC inhibitors, such as TSA and SAHA, has anti-inflammatory effects in several autoimmune diseases, including RA and SLE ${ }^{[16,21,22,34]}$. In the current study, IgG containing anti-HDAC-3 Ab from normal individuals inhibited the HDAC-3 enzymatic activity, while such inhibitory effect was not observed in IgG from SSc patients. In contrast, IgM isolated from serum samples from healthy individuals and SSc patients did not significantly inhibit the HDAC-3 activity (data not shown). As the inflammation induced by autoimmune responses plays a role in the induction and development of SSc ${ }^{[35]}$, the decreased levels of anti-HDAC-3 Ab might contribute to the inflammation of SSc. Indeed, a recent study has revealed that TSA prevents the expression of total collagen protein in SSc skin fibroblasts by decreasing cytokine production in vitro ${ }^{[23]}$, suggesting that skin fibrosis in SSc may be related to the enhanced HDAC function resulting from the absence of anti-HDAC-3 Ab.

Accumulating evidences have indicated that some autoantibodies play protective roles in many situations ${ }^{[36]}$. Natural autoantibodies, which are generated in the absence of specific immunization or foreign antigen ${ }^{[37]}$, remove circulating products including immunogenic autoantigens before inducing autoimmune responses ${ }^{[36]}$. The presence of IgM anti-double strand DNA Abs is found to be significantly associated with milder disease activity in SLE, in particular, with the absence of lupus nephritis ${ }^{[38]}$. A highly significant correlation of rheumatoid factor with the absence of kidney disease is also 
observed $^{[39]}$. Furthermore, the presence of anti-La autoantibody is associated with lower risk of nephritis and seizures in SLE ${ }^{[40]}$. Considering the fact that inhibition of the HDAC activity has anti-inflammatory effects, these findings raise the possibility that anti-HDAC-3 Ab may be one of the protective autoantibodies. Furthermore, the finding that serum levels of anti-HDAC-3 Ab in healthy controls significantly increased compared with SSc patients suggests that anti-HDAC-3 Ab may also belong to natural autoantibody. However, it should be noted that it remained unknown in this study whether anti-HDAC-3 Ab could indeed inhibit the activity of an intracellular enzyme HDAC-3 in vivo. Alternatively, it is possible that the lack of IgG anti-HDAC-3 Ab production in SSc may simply reflect immunological abnormalities of B cells, T cells, and antigen-presenting cells. Nonetheless, the results of this study suggest that immune responses against HDAC-3 are different between SSc patients and healthy individuals, which would be a clue for understanding the immunological abnormalities in SSc. 


\section{REFERENCES}

[1] Sato S, Hayakawa I, Hasegawa M, Fujimoto M, Takehara K. Function blocking autoantibodies against matrix metalloproteinase- 1 in patients with systemic sclerosis. J Invest Dermatol 2003; 120:542-7.

[2] White B. Immunopathogenesis of systemic sclerosis. Rheum Dis Clin North Am 1996; 22:695-708.

[3] Okano Y. Antinuclear antibody in systemic sclerosis (scleroderma). Rheum Dis Clin North Am 1996; 22:709-35.

[4] Xu WS, Parmigiani RB, Marks PA. Histone deacetylase inhibitors: molecular mechanisms of action. Oncogene 2007; 26:5541-52.

[5] Zhang X, Wharton W, Yuan Z, Tsai SC, Olashaw N, Seto E. Activation of the growth-differentiation factor 11 gene by the histone deacetylase (HDAC) inhibitor trichostatin A and repression by HDAC3. Mol Cell Biol 2004; 24:5106-18.

[6] de Ruijter AJ, van Gennip AH, Caron HN, Kemp S, van Kuilenburg AB. Histone deacetylases (HDACs): characterization of the classical HDAC family. Biochem J 2003; 370:737-49.

[7] Yang XJ, Gregoire S. Class II histone deacetylases: from sequence to function, regulation, and clinical implication. Mol Cell Biol 2005; 25:2873-84.

[8] Porcu M, Chiarugi A. The emerging therapeutic potential of sirtuin-interacting drugs: from cell death to lifespan extension. Trends Pharmacol Sci 2005; 26:94-103.

[9] Mahlknecht U, Will J, Varin A, Hoelzer D, Herbein G. Histone deacetylase 3, a class I histone deacetylase, suppresses MAPK11-mediated activating 
transcription factor-2 activation and represses TNF gene expression. J Immunol 2004; 173:3979-90.

[10] Herranz M, Esteller M. New therapeutic targets in cancer: the epigenetic connection. Clin Transl Oncol 2006; 8:242-9.

[11] Cress WD, Seto E. Histone deacetylases, transcriptional control, and cancer. J Cell Physiol 2000; 184:1-16.

[12] Glaser KB, Li J, Staver MJ, Wei RQ, Albert DH, Davidsen SK. Role of class I and class II histone deacetylases in carcinoma cells using siRNA. Biochem Biophys Res Commun 2003; 310:529-36.

[13] Johnstone RW. Histone-deacetylase inhibitors: novel drugs for the treatment of cancer. Nat Rev Drug Discov 2002; 1:287-99.

[14] Chung YL, Lee MY, Wang AJ, Yao LF. A therapeutic strategy uses histone deacetylase inhibitors to modulate the expression of genes involved in the pathogenesis of rheumatoid arthritis. Mol Ther 2003; 8:707-17.

[15] Piekarz R, Bates S. A review of depsipeptide and other histone deacetylase inhibitors in clinical trials. Curr Pharm Des 2004; 10:2289-98.

[16] Huang L. Targeting histone deacetylases for the treatment of cancer and inflammatory diseases. J Cell Physiol 2006; 209:611-6.

[17] Bode KA, Schroder K, Hume DA, Ravasi T, Heeg K, Sweet MJ, et al. Histone deacetylase inhibitors decrease Toll-like receptor-mediated activation of proinflammatory gene expression by impairing transcription factor recruitment. Immunology 2007; 122:596-606.

[18] Adcock IM. HDAC inhibitors as anti-inflammatory agents. Br J Pharmacol 2007; 150:829-31. 
[19] Lin HS, Hu CY, Chan HY, Liew YY, Huang HP, Lepescheux L, et al. Anti-rheumatic activities of histone deacetylase (HDAC) inhibitors in vivo in collagen-induced arthritis in rodents. Br J Pharmacol 2007; 150:862-72.

[20] Huang N, Katz JP, Martin DR, Wu GD. Inhibition of IL-8 gene expression in Caco-2 cells by compounds which induce histone hyperacetylation. Cytokine 1997; 9:27-36.

[21] Mishra N, Reilly CM, Brown DR, Ruiz P, Gilkeson GS. Histone deacetylase inhibitors modulate renal disease in the MRL-lpr/lpr mouse. J Clin Invest 2003; 111:539-52.

[22] Reilly CM, Mishra N, Miller JM, Joshi D, Ruiz P, Richon VM, et al. Modulation of renal disease in MRL/lpr mice by suberoylanilide hydroxamic acid. J Immunol 2004; 173:4171-8.

[23] Huber LC, Distler JH, Moritz F, Hemmatazad H, Hauser T, Michel BA, et al. Trichostatin A prevents the accumulation of extracellular matrix in a mouse model of bleomycin-induced skin fibrosis. Arthritis Rheum 2007; 56:2755-64.

[24] Shebzukhov YV, Koroleva EP, Khlgatian SV, Belousov PV, Kuz'mina KE, Radko $\mathrm{BV}$, et al. Antibody response to a non-conserved C-terminal part of human histone deacetylase 3 in colon cancer patients. Int J Cancer 2005; 117:800-6.

[25] Preliminary criteria for the classification of systemic sclerosis (scleroderma). Subcommittee for scleroderma criteria of the American Rheumatism Association Diagnostic and Therapeutic Criteria Committee. Arthritis Rheum 1980; 23:581-90.

[26] LeRoy EC, Black C, Fleischmajer R, Jablonska S, Krieg T, Medsger TA, Jr., et al. Scleroderma (systemic sclerosis): classification, subsets and pathogenesis. J 
Rheumatol 1988; 15:202-5.

[27] Tan EM, Cohen AS, Fries JF, Masi AT, McShane DJ, Rothfield NF, et al. The 1982 revised criteria for the classification of systemic lupus erythematosus. Arthritis Rheum 1982; 25:1271-7.

[28] Bohan A, Peter JB. Polymyositis and dermatomyositis (second of two parts). N Engl J Med 1975; 292:403-7.

[29] Bohan A, Peter JB. Polymyositis and dermatomyositis (first of two parts). N Engl J Med 1975; 292:344-7.

[30] Sato S, Hasegawa M, Fujimoto M, Tedder TF, Takehara K. Quantitative genetic variation in CD19 expression correlates with autoimmunity. J Immunol 2000; 165:6635-43.

[31] Miyakawa H, Kikuchi K, Kitazawa E, Kawaguchi N. Anti-pyruvate dehydrogenase complex-E2 antibody immunoglobulin class switch from IgM to IgG in long-term follow-up patients with primary biliary cirrhosis. Hepatol Res 2002; 22:167-173.

[32] Liu S, Cerutti A, Casali P, Crow MK. Ongoing immunoglobulin class switch DNA recombination in lupus B cells: analysis of switch regulatory regions. Autoimmunity 2004; 37:431-43.

[33] Phan TG, Amesbury M, Gardam S, Crosbie J, Hasbold J, Hodgkin PD, et al. B cell receptor-independent stimuli trigger immunoglobulin (Ig) class switch recombination and production of IgG autoantibodies by anergic self-reactive B cells. J Exp Med 2003; 197:845-60.

[34] Nishida K, Komiyama T, Miyazawa S, Shen ZN, Furumatsu T, Doi H, et al. Histone deacetylase inhibitor suppression of autoantibody-mediated arthritis in 
mice via regulation of p16INK4a and p21(WAF1/Cip1) expression. Arthritis Rheum 2004; 50:3365-76.

[35] Stephanie Gu Y, Kong J, Cheema GS, Keen CL, Wick G, Gershwin ME. The Immunobiology of Systemic Sclerosis. Semin Arthritis Rheum 2008.

[36] Shoenfeld Y, Toubi E. Protective autoantibodies: role in homeostasis, clinical importance, and therapeutic potential. Arthritis Rheum 2005; 52:2599-606.

[37] Shoenfeld Y, Isenberg DA. The mosaic of autoimmunity. Immunol Today 1989; $10: 123-6$.

[38] Bootsma H, Spronk PE, Hummel EJ, de Boer G, ter Borg EJ, Limburg PC, et al. Anti-double stranded DNA antibodies in systemic lupus erythematosus: detection and clinical relevance of IgM-class antibodies. Scand J Rheumatol 1996; 25:352-9.

[39] Tarkowski A, Westberg G. Rheumatoid factor isotypes and renal disease in systemic lupus erythematosus. Scand J Rheumatol 1987; 16:309-12.

[40] Malik S, Bruner GR, Williams-Weese C, Feo L, Scofield RH, Reichlin M, et al. Presence of anti-La autoantibody is associated with a lower risk of nephritis and seizures in lupus patients. Lupus 2007; 16:863-6. 


\section{FIGURE LEGENDS}

Fig. 1. IgG (A) and IgM (B) anti-HDAC-3 Ab levels in serum samples from patients with SSc, DM, or SLE and healthy controls (CTL). Anti-HDAC-3 Ab levels were determined by ELISA using human recombinant HDAC-3. The short bar indicates the mean value in each group.

Fig. 2. Immunoblotting analysis of IgG anti-HDAC-3 Ab in serum samples from patients with SSc, DM, or SLE and normal individuals. Lanes 1 and 2: normal individuals. Lane 3: a DM patient. Lane 4: a SLE patient. Lanes 5 and 6: SSc patients. These results represent 5 SSc patients, 5 SLE patients, 5 DM patients, and 5 healthy individuals. Serum samples from patients with SLE or DM and healthy individuals whose levels of IgG anti-HDAC-3 Ab were higher than the highest OD value of SSc patients by ELISA were selected for immunoblotting analysis.

Fig. 3. Inhibition of the HDAC-3 enzymatic activity by IgG isolated from serum samples of SSc patients and from those of normal control (CTL). The HDAC-3 activity was evaluated by ELISA using the fluorimetric histone deacetylase lysyl substrate that comprises an acetylated lysine side chain. The HDAC-3 enzymatic activity is shown as percentage of IgG-untreated HDAC-3 (HDAC-3 control) that was defined as $100 \%$. Each histogram shows the mean (+ SD) values obtained from 10 subjects of each group. Serum samples from healthy individuals whose levels of IgG anti-HDAC-3 Ab were higher than the highest OD value of SSc patients by ELISA were selected for the HDAC-3 activity assay. 
A. IgG anti-HDAC-3 Ab

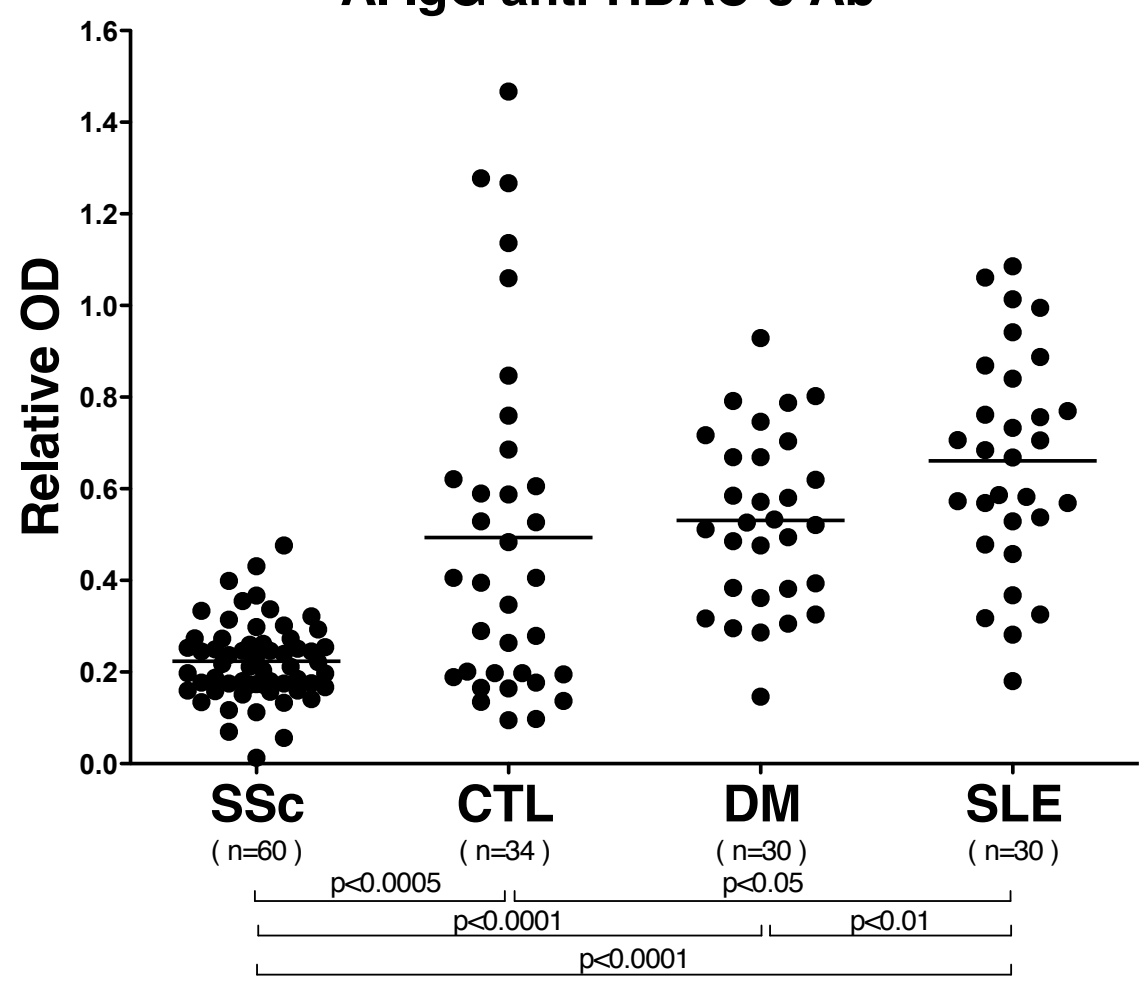

B. IgM anti-HDAC-3 Ab

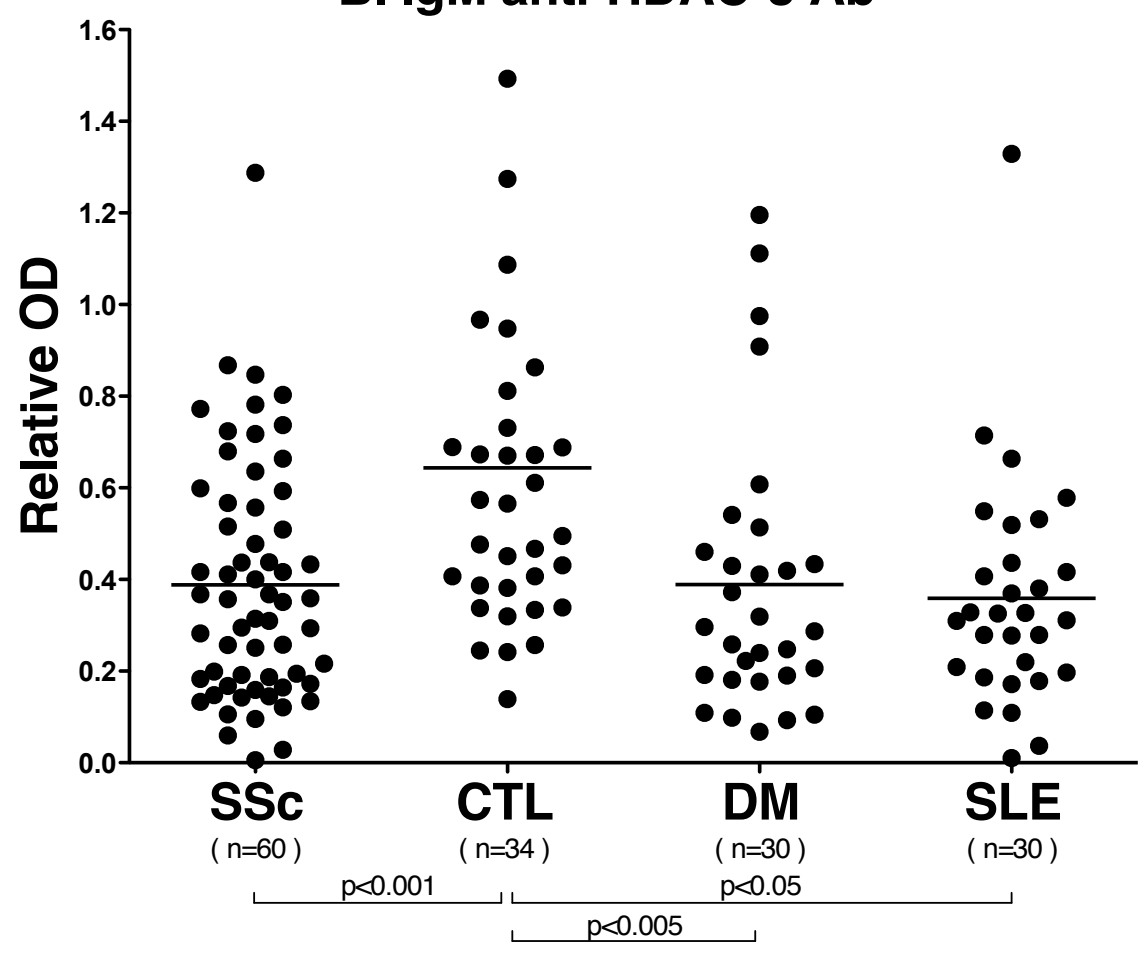




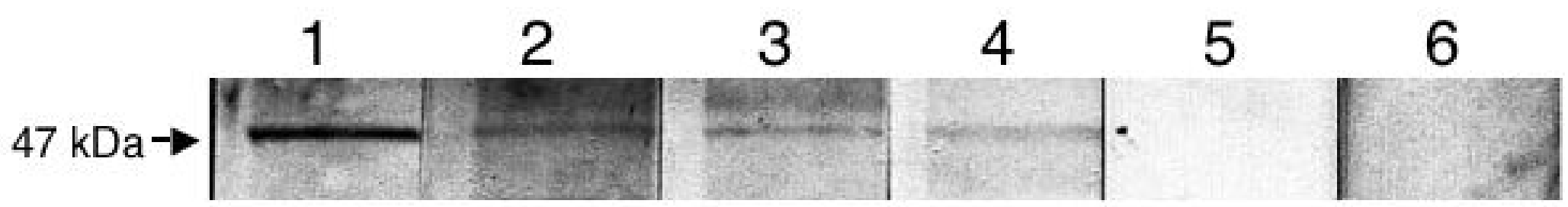

Kuwatsuka $\mathrm{Y}$ et al. Figure 2 


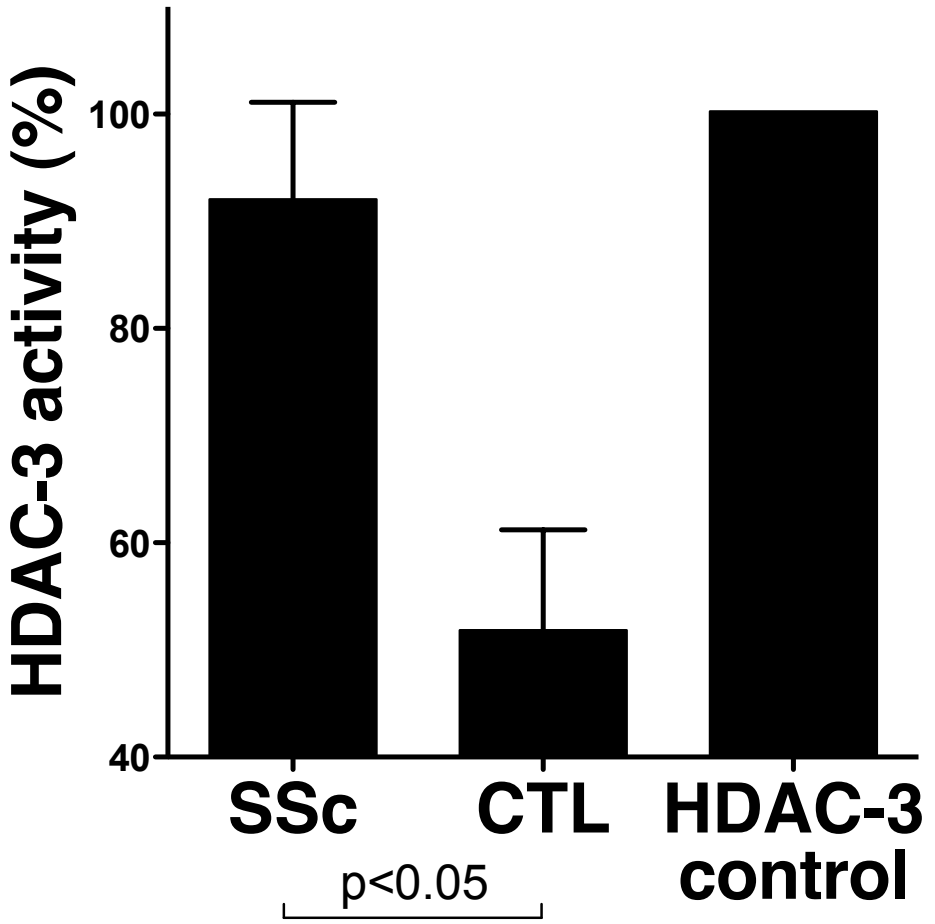

Kuwatsuka Y et al. Figure 3 